\title{
Water Requirement Modelling for Wheat under Arid Climatic Conditions
}

\author{
Laaboudi $\mathrm{A}^{1 *}$ and Mouhouche $\mathrm{B}^{2}$ \\ ${ }^{1}$ Algerian Institute for Research in Agronomy, Experimental Station of Adrar, Algeria \\ ${ }^{2}$ National High School of Agronomy, Algeria
}

\begin{abstract}
Algeria is an agriculture country where wheat is staple food of this region. Wheat is a winter crop and sown almost throughout the country. Winter season starts from October and normally ends in April. Water requirement of wheat followed variations in terms of location and time of the season. The northern of the country receives good rains during growth stages of wheat. But the southern of the country always requires irrigation and the groundwater is used extensively. Thousands of hectares are irrigated by pivot centres in extreme weather conditions. Better manage of limited water resources is the main objective of this study. Estimation of wheat maximum evapotranspiration with a Semi empirical approach used directly by the farmers, in lack of meteorological parameters, allows reaching this objective.

The water balance of wheat was obtained by using non-weighing lysimeters. It was found that the Maximum daily crop Evapotranspiration (MET) for each wheat growth stage is linked to mean of daily temperature $\left(\mathrm{Tm}{ }^{\circ} \mathrm{C}\right)$ and Leaf Area Index (LAI).

Multivariate analysis shows that LAI does not contribute significantly for realizing a model in case of linear correlation. Using mean temperature of each growth stage, the obtained result shows a strong correlation between the calculated values of maximum evapotranspiration and its simulated values. In case of non linear correlation, both $\mathrm{LAl}$ and mean temperature contribute significantly for construction of the model. In this case the performance criteria are satisfactory. The determination coefficient $\left(\mathrm{R}^{2}\right)$, Nash-Sutcliffe efficiency and the Relative Mean-Squared Error (RMSE) are respectively: $0.92,0.92$ and $0.75 \mathrm{~mm} /$ day.
\end{abstract}

Keywords: Arid region; Limited water resources; Wheat; Semi empirical approach; Multivariate analysis

\section{Introduction}

The great challenge for the coming decades will be the task of increasing food production to ensure food security for the steadily growing population. However, the dependency on water for food production has become a critical constraint for increasing food production in many regions that face the serious water deficiency [13]. Hence, according to Naeem and Rai [4], water shortage requires developing new technologies and methods of irrigation that can be helpful to utilize this precious input in an effective way. In addition, there is also a need to carry out practices of irrigation water management to achieve high water use efficiency and to increase the productivity of existing water resources and also to produce more food with less water [5]. This necessitates innovative and sustainable research and an appropriate transfer of technologies [6].

It should be noted that in many regions of the world, climate changes will increase the average reference evapotranspiration by $2 \%$ [7] and then increasingly affects cultivation water requirements [8].

In Algeria, despite successes of government investments to mobilize additional supplies of potable water and industrial water, irrigation have failed to match the growing demand. Recent droughts have exposed the vulnerability of large-scale irrigation systems and the pressure on groundwater resources. At the same time, new demands are emerging for major investment in wastewater treatment to counter the continuing threat that untreated sewage poses for health and long-term sustainability of the country's water resources [9].

Available water appeared as the most important factor limiting wheat crop yields under the semi arid highland of eastern Algeria. The amount of grain yield produce per water use increased with the increase of availability of soil water and consequently water used efficiency increased [10]. That is why, development of the irrigation sector and improvement of its planning system as part of the small-scale irrigation project activities are a big challenge for the government of Algeria.

People who live in the Sahara have traditionally exploited the availability of underground water thanks to Foggara irrigation, which creates green oases, but for the sustainable development of oasis ecosystem, it is important to clarify an exact distribution of oasis landuse type where the excessive waste of the flood irrigation method has broken the balance between the water supply and requirement. Recently, thousands of hectares are irrigated by pivot centers without knowledge of crop water requirement. This has affected the groundwater level and an imported number of Foggaras are stopped.

This is why; the accurate estimation of crop water requirements in the arid and semi-arid regions is crucial and important for sound water-use efficiency [11].

Furthermore, according to Hajare et al. [12], knowledge of exact amount of water required by different crops in a given set of climatological condition of a region is great help in planning of irrigation scheme, irrigation scheduling, effective design and management of irrigation system.

*Corresponding author: Laaboudi A, Algerian Institute for Research in Agronomy, Experimental Station of Adrar, France, Tel: 213499683 85; Fax: 213499683 85; E-mail: Laaboudiaek@yahoo.fr

Received March 12, 2012; Accepted April 11, 2012; Published April 18, 2012

Citation: Laaboudi A, Mouhouche B (2012) Water Requirement Modelling for Wheat under Arid Climatic Conditions. Hydrol Curr Res 3:130. doi:10.4172/21577587.1000130

Copyright: ( 2012 Laaboudi A, et al. This is an open-access article distributed under the terms of the Creative Commons Attribution License, which permits unrestricted use, distribution, and reproduction in any medium, provided the original author and source are credited. 
Citation: Laaboudi A, Mouhouche B (2012) Water Requirement Modelling for Wheat under Arid Climatic Conditions. Hydrol Curr Res 3:130. doi:10.4172/2157-7587.1000130

Page 2 of 6

Indeed, the reference evapotranspiration is an important quantity for computing the irrigation demands for various crops [13]. Current irrigation scheduling is based on a well-established crop coefficient and on reference evapotranspiration procedures to estimate daily crop evapotranspiration [14] that is why, a poor ET calculation appeared to be associated with poor estimations of the ET0 [15].

Producers of hard wheat know that inadequate water reduces yield and quality. So, they often ask, how much water will my crop need before I can turn the water off? How much water to apply?

In order to response on these questions, we carried out this research for compute water requirements of wheat in this region. Because the leaf area index (LAI) is a parameter that reflects the development of plant stands. It is connected with photosynthesis as well as with transpiration and, to a certain degree, also with the aboveground biomass of the stand [16]. We tried in this study to apply a Semi empirical Approach to develop a practical model, using as inputs the average daily temperature $\left(\mathrm{Tm}^{\circ} \mathrm{C}\right)$ and leaf area index (LAI).

\section{Materials and Methods}

\section{Site description}

Our study was realized in the region of Adrar, located in the southwest of Algeria. Latitude: $27^{\circ} 49^{\prime} \mathrm{N}$ and Longitude: $00^{\circ} 18^{\prime} \mathrm{E}$ (Figure1). Adrar is characterized by its extreme meteorological parameters.

Climate characteristics: Adrar's climate is dry throughout the

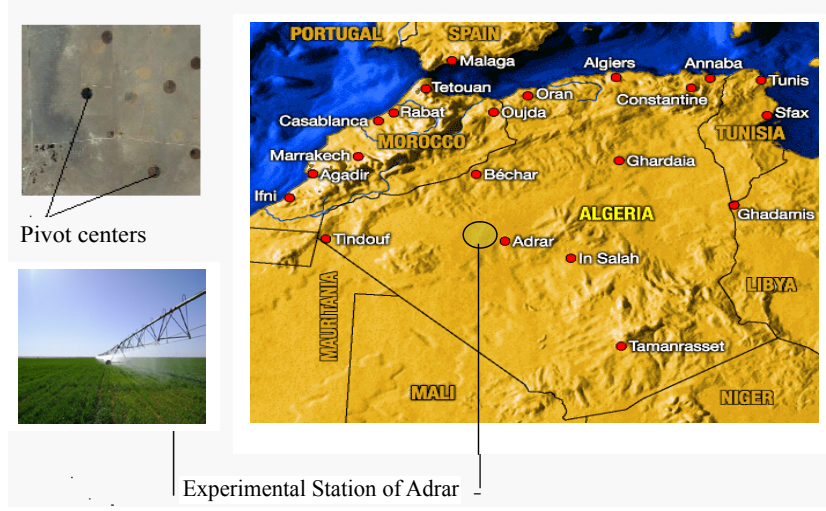

Figure 1: Sketch of the investigation area.

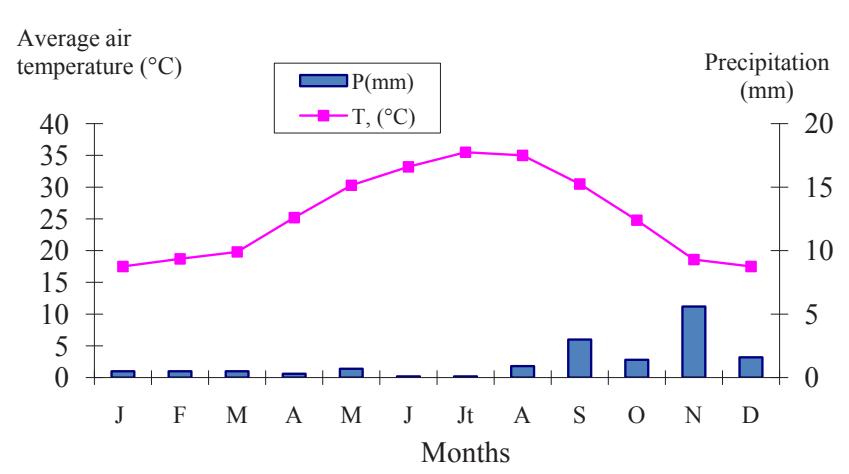

Figure 2: Ombrothermic diagram of Bagnauls and Gaussen of the region of Adrar (average of 25 years). Where $P$ is the precipitation $(\mathrm{mm}), T$ is the average air temperature $\left({ }^{\circ} \mathrm{C}\right)$.

\begin{tabular}{|l|c|c|c|c|c|}
\hline & Clay \% & $\begin{array}{c}\text { Fine Loam } \\
\%\end{array}$ & $\begin{array}{c}\text { Coarse loam } \\
\%\end{array}$ & $\begin{array}{c}\text { Fine sand } \\
\%\end{array}$ & $\begin{array}{c}\text { Coarse sand } \\
\%\end{array}$ \\
\hline pivot center & 7.04 & 12.5 & 44.2 & 57.9 & 10.1 \\
\hline $\begin{array}{l}\text { Experimental } \\
\text { station }\end{array}$ & 6.8 & 3.9 & 4,74 & 63.6 & 21.3 \\
\hline
\end{tabular}

Table 1: soil physical properties.

year as shown in the ombrothermic diagram (Figure 2). The climate is characterized by the extended thermal amplitudes during the year, the month and even the day. The absolute maximum temperature reaches $49.5^{\circ} \mathrm{C}$ in summer (July and August). On the contrary, ice and frosts are rare in this region. Nevertheless, icy days can cause catastrophic damages, especially to traditional farming. Furthermore, it has recorded:

- A negligible pluviometry ( $<25 \mathrm{~mm} /$ year).

- A relative humidity often below $50 \%$. The dew is very rare.

- A North-East wind blows almost constantly.

- A fluently clear sky with intense brightness.

Where $\mathrm{P}$ is the precipitation $(\mathrm{mm}), \mathrm{T}$ is the average air temperature $\left({ }^{\circ} \mathrm{C}\right)$

The experiment was conducted in experimental station and also with a farmer under the pivot center.

The observations are noted during all growth stages of wheat. They have concerned the vegetal development and the leaf area index evolution. Each day, the water balance is calculated. Water management practices are sprinkler system under pivot center at farmer and flood irrigation system at experimental station. The lysimeters was watered by daily quantity of supply water according to the growth stages of wheat.

Soil physical properties are as follow (Table 1):

Estimation of reference evapotranspiration: Next is the Penman-Montheith equation that is used for calculating the reference evapotranspiration; it was proposed by Allen et al. [17]:

$$
\mathrm{ET0}=\frac{0.408 \Delta\left(R_{n}-G\right)+\gamma \frac{900}{T+273} u_{2}\left(e_{s}-e_{a}\right)}{\Delta+\gamma\left(1+0.34 u_{2}\right)}
$$

Where ET0 is the reference evapotranspiration $\left[\mathrm{mm} \mathrm{day}^{-1}\right] . \mathrm{R}_{\mathrm{n}}$ is the net radiation at the crop surface $\left[\mathrm{MJ} \mathrm{m} \mathrm{m}^{-2} \mathrm{day}^{-1}\right]$. $\mathrm{G}$ is the soil heat flux density $\left[\mathrm{MJ} \mathrm{\textrm {m } ^ { - 2 } \text { day }}{ }^{-1}\right]$. $\mathrm{T}$ is the mean of daily air temperature at $2 \mathrm{~m}$ height $\left[{ }^{\circ} \mathrm{C}\right] . \mathrm{u}_{2}$ is the wind speed at $2 \mathrm{~m}$ height $\left[\mathrm{m} \mathrm{s}^{-1}\right] . \mathrm{e}_{\mathrm{s}}$ is the saturation vapour pressure $[\mathrm{kPa}] . \mathrm{e}_{2}$ is the actual vapour pressure $[\mathrm{kPa}] . \mathrm{e}_{\mathrm{s}}-\mathrm{e}_{2}$ is the saturation vapour pressure deficit $[\mathrm{kPa}] . \Delta$ is the slope vapour pressure curve $\left[\mathrm{kPa}^{\circ} \mathrm{C}^{-1}\right] . \gamma$ is the psychometric constant $\left[\mathrm{kPa}^{\circ} \mathrm{C}^{-1}\right]$.

\section{Experimental treatments and measurements}

Experiments on winter wheat were conducted in three consecutive winter wheat seasons between 2005-2007. There are four non-weighing lysimeters used for the water balance estimation.

Maximum evapotranspiration of wheat (MET): The daily maximum evapotranspiration values of wheat are determinate by nonweighing lysimeters. Using the water balance, MET is the difference between the input water and output water.

Lysimetry in its simplest form involves the volumetric measurement of all incoming and outgoing water of a container which encloses an isolated soil mass with vegetated surface. This incoming and outgoing water flux can be represented in a water balance, expressed as: 


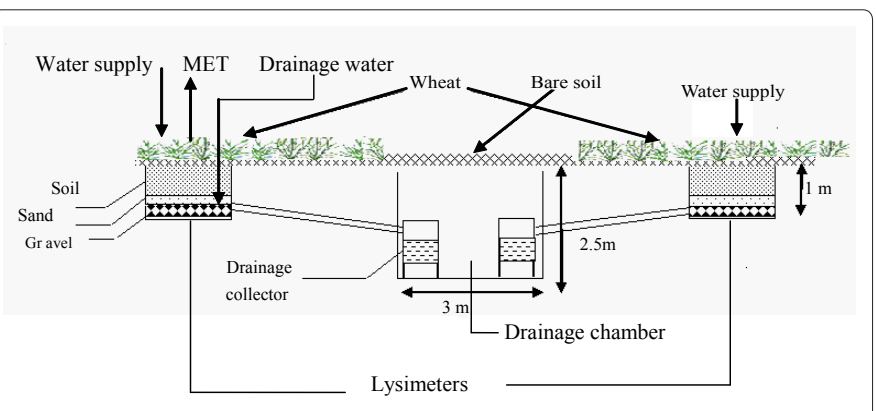

Figure 3: Scheme of two non weighing lysimeters.

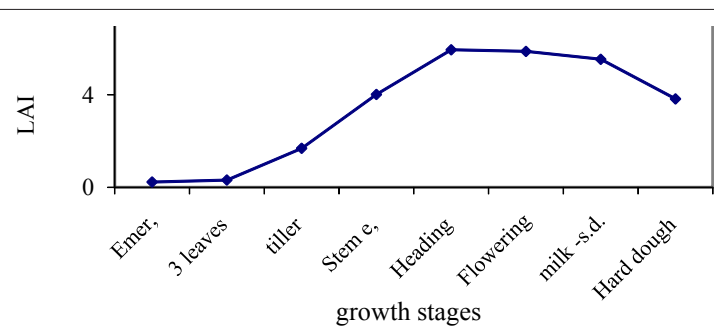

Figure 4: LAl evolution according wheat growth stages

$$
\mathrm{P}+\mathrm{I} \pm \mathrm{Ro}=\mathrm{MET}+\mathrm{D} \pm \Delta \mathrm{W}
$$

The incoming water flux for a given time period refers to $\mathrm{P}=$ precipitation and I = irrigation

The outgoing water flux refers to MET = maximum evapotranspiration of the crop and $\mathrm{D}=$ drainage water.

Ro and $\Delta \mathrm{W}$ are respectively surface runoff and change of water content $(w)$ of the isolated soil mass over a given period. In our case both these terms are $=0$, and MET can then be determined directly by:

$$
\mathrm{MET}=\mathrm{P}+\mathrm{I}-\mathrm{D}
$$

Each lysimeter has 1meter depth and 1meter of diameter (Figure 3). The special arrangements are made within the lysimeter to drain and measure the water percolating through the soil mass. A special drainage chamber and calibrated container is used to collect and measure the percolated water.

Data collection: The meteorological data were collected from weather station of Experiment farm. Meteorological data are available for precipitation, relative humidity, hours of sunshine duration, air temperature, and wind speed.

Leaf area index (LAI): LAI of wheat was measured after emergence at each growth stage during the whole growing season. A sample area of $1 \mathrm{~m}^{2}$ is selected and all plants in the area are collected.

Leaf length and the greatest leaf width were measured with ruler and leaf area is determined by following formula:

Leaf area $\left(\mathrm{cm}^{2}\right)=$ leaf length ${ }^{*}$ the greatest leaf width ${ }^{\star} 0.75(4)$

LAI is set as the ratio of total leaf area to land area over an experimental plot.

Model evaluation: Accuracies based on the following statistical criteria:

The Nash-Sutcliffe Efficiency (E) was proposed by Nash and Sutcliffe. It is calculated by formula (5) according to Krause et al. [18].
The squared value of the correlation coefficient (R), the Root Mean Squared Error (RMSE), the Mean-Squared Error (MSE) and the Mean Absolute Relative Error (MARE) were calculated as follows:

$$
\begin{aligned}
& E=1-\frac{\sum_{i=1}^{n}\left(Y_{\text {sim }}-Y_{\text {obs }}\right)^{2}}{\sum_{i=1}^{n}\left(Y_{\text {sim }}-\bar{Y}_{\text {obs }}\right)^{2}} \\
& R=\frac{\sum_{i=1}^{n}\left(Y_{\text {obs }}-\bar{Y}_{\text {obs }}\right)\left(Y_{\text {sim }}-\bar{Y}_{\text {sim }}\right)}{\sqrt{\sum_{i=1}^{n}\left(Y_{o b s}-\bar{Y}_{\text {obs }}\right)} \sqrt{\sum_{i=1}^{n}\left(Y_{\text {sim }}-\bar{Y}_{\text {sim }}\right)}} \\
& R M S E=\sqrt{\frac{\sum_{i=1}^{n}\left(Y_{o b s}-Y_{\text {sim }}\right)^{2}}{n}} \\
& \text { MARE }=\frac{1}{n} \sum_{i=1}^{n} \frac{\left|Y_{\text {obs }}-Y_{\text {sim }}\right|}{\left|Y_{\text {obs }}\right|} \times 100
\end{aligned}
$$

With E-Nash- Sutcliffe efficiency, $\mathrm{Y}_{\text {sim }}$ - Simulated variable, $\mathrm{Y}_{\mathrm{obs}}$ Observed variable, $\bar{Y}_{s i m}-$ Average of Simulated variable, $\bar{Y}_{\text {obs }}$-Average of observed variable, $\mathrm{n}$-Number of observations.

In order to evaluate contribution of each parameter, they are added the test of non co linearity using Variance Inflation Factor (VIF), significance test of $\mathrm{F}$ statistical and T statistical.

Crop coefficient: Using non-weighing lysimeters and Penman Monteith formula, we evaluate the Crop coefficient Kc as fallow:

$$
K c=\frac{M E T}{E T 0}
$$

Where Kc crop coefficient, MET maximum evapotranspiration (mm/day) and ET0 reference evapotranspiration ( $\mathrm{mm} /$ day)

\section{Results and Discussion}

\section{Leaf Area Development}

Early in the plant growth, the leaf area is small. The rate of leaf area establishment depends on temperature, but can be increased by high nitrogen fertilization and seeding rates. From tiller stage, it occurs the high speed growth of leaf area. The maximum leaf area is usually reached about heading stage (Figure 4), and then declines during grain growth, because of senescence of wheat leaves. As the lower leaves die, the upper leaf blades leaf sheaths and heads become very important as photosynthetic sources for grain filling.

The variance analysis indicates a significant difference $(\mathrm{P}<0.01)$ between the LAI values for each test campaign. This shows that LAI is not a varietal character. It may change with changing environmental conditions, as sowing density [19] and higher salt sensitivity [20]. In our case (Figure 5) this difference mainly due to variations of climatic

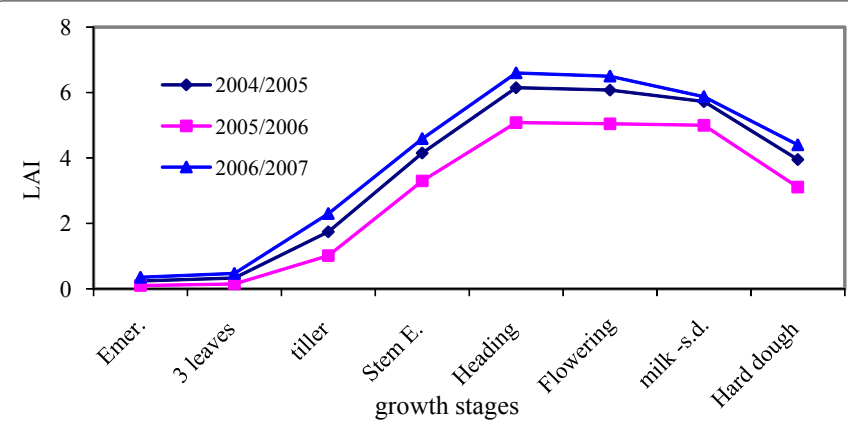

Figure 5: LAl evolution according wheat growth stages during three test campaigns . 


\begin{tabular}{|l|c|c|c|c|}
\hline Growth stages & $2004 / 2005$ & $2005 / 2006$ & $2006 / 2007$ & average \\
\hline Emergence & 1.07 & 1.79 & 1.47 & 1.44 \\
\hline 3 leaves & 1.68 & 1.74 & 2.02 & 1.81 \\
\hline Tiller & 4.39 & 3.07 & 2.52 & 3.33 \\
\hline Stem elongation & 7.48 & 4.23 & 4.16 & 5.29 \\
\hline Heading & 7.68 & 4.3 & 5.45 & 5.81 \\
\hline Flowering & 9.86 & 6.8 & 6.18 & 7.61 \\
\hline milk -soft dough & 9.24 & 9.1 & 6.92 & 8.42 \\
\hline Hard dough & 6.18 & 6.43 & 5.49 & 6.03 \\
\hline
\end{tabular}

Table 2: the amount of water consumed by wheat (MET) during the vegetative stages $(\mathrm{mm} /$ day) in the three.

\begin{tabular}{|l|c|c|c|c|}
\hline \multicolumn{1}{|c|}{ Growth stages } & $2004 / 2005$ & $2005 / 2006$ & $2006 / 2007$ & average \\
\hline Emergence & 0.35 & 0.55 & 0.54 & 0.48 \\
\hline 3 leaves & 0.56 & 0.86 & 0.79 & 0.74 \\
\hline tiller & 1.2 & 1.04 & 0.97 & 1.07 \\
\hline Stem elongation & 1.4 & 1.29 & 1.18 & 1.29 \\
\hline Heading & 1.43 & 1.34 & 1.22 & 1.33 \\
\hline Flowering & 1.57 & 1.39 & 1.36 & 1.44 \\
\hline milk -soft dough & 1.44 & 1.39 & 1.23 & 1.35 \\
\hline Hard dough & 0.92 & 0.84 & 0.87 & 0.88 \\
\hline
\end{tabular}

Table 3: Evolution of crop coefficient $(\mathrm{Kc})$ of wheat during growth stages.

conditions during the growth cycle of each campaign. The maximum value of LAI is 6.6, almost equal 6.5 found by Bavec et al. [21].

\section{Maximum crop evapotranspiration (METo):}

The values of measured MET over the growing season during three test campaigns are depicted in table 2. They show that as the crop develops and shades more and more of the ground, evaporation becomes more restricted and transpiration gradually becomes the major process. Total water use during the growing period was 592 $\mathrm{mm}, 615 \mathrm{~mm}$ and $604 \mathrm{~mm}$ respectively during the first, second and third season. These are higher than $427 \mathrm{~mm}$ (16.8 inches) reported by Charles \& Paul [22] for wheat in central Arizona.

At the mid-season stages, the values of MET are higher than at other stages of wheat crop. These results are connected with those of Bing et al. [23] found that MET increased with the development of the growing season and reaches a maximum when LAI was greatest. Then it decreased gradually.

\section{Crop coefficients $(\mathrm{Kc})$ average:}

After determining ET0, the MET or Crop Water Requirement (CWR) can be calculated using the appropriate crop-coefficient $(\mathrm{Kc})$ using formula (9).

Crop coefficient $(\mathrm{Kc})$ is actually the ratio of maximum crop evapotranspiration to reference crop evapotranspiration. For wheat, this ratio can reach 1.5 during the reproductive cycle (heading to grain formation) otherwise it remains less than 1 bearing minimum values during the early age of the crop and at maturity (table 3 ).

It should be noted that $\mathrm{Kc}$ of the young plants is lower. Then it increases gradually to reach a maximum value for flowering stage. Then it decreases thereafter. This value is higher than 1.24 reported by Tyagi et al. [24] but it is very closer than 1.42 obtained by Yongqiang et al. [25].
Note that the values of Kc are agreed very well in different growth seasons, because, statistical analysis showed that there was no significant difference between the values of crop coefficient in the various test seasons.

\section{Maximum evapotranspiration modelling:}

To contribute in the construction of the model, the $\mathrm{T}$ statistical value of each parameter must be greater than $\mathrm{T}$ critical value. In our case the $\mathrm{T}$ critical value at confidence interval $\alpha=0.05$ is 2.085 .

Actually we have two options. In the first, when we use linear relation; in this case the statistical value of LAI is 0.72 . Therefore, this parameter does not contribute for the construction of the model and we can eliminate. The formula of model obtained is given as follow:

$\mathrm{MET}=0.27 \mathrm{~T}+4.76 \mathrm{Kc}-4.99$

Where MET is maximum evapotranspiration ( $\mathrm{mm} /$ day), $\mathrm{T}$ is the average daily temperature $\left({ }^{\circ} \mathrm{C}\right)$ and $\mathrm{Kc}$ is the wheat crop coefficient.

Observed F (93.48) was higher than critical F (3.10). That is mean; $\mathrm{R}^{2}$ is highly significant. Generally, all the parameters used in the models have significantly contributed in estimating MET. Results showed at confidence level of $\alpha=0.05$ indicate that the marginal contribution of each variable is significant, (table 4 ).

The performances criteria show that the model is well performed. The Nash efficiency value is 0.89 . The mean squared error, root mean squared error and mean absolute relative values are respectively 0.66 $(\mathrm{mm} / \text { day })^{2}, 0.81(\mathrm{~mm} /$ day $)$ and $21.16 \%$.

The second option, when we use non linear relation in this case the statistical value of LAI is 2.47 . Therefore, this parameter contributes significantly for building the model. The formula of this model is given as follow:

$$
\mathrm{MET}=\exp \left(0.26 \mathrm{LAI}^{-0.5}+0.046 \mathrm{~T}+0.95 \mathrm{Kc}-0.83\right)
$$

Where MET is maximum evapotranspiration ( $\mathrm{mm} /$ day), $\mathrm{T}$ is the mean daily temperature $\left({ }^{\circ} \mathrm{C}\right)$, LAI is the leaf area index and $\mathrm{Kc}$ is the crop coefficient

The data statistical analysis shows a close relationship between the observed and the simulated series; the determination coefficient $\mathrm{R}^{2}$ reached 92\%. They also showed that observed F (127.68) was higher than critical $\mathrm{F}$ (3.10). That means all parameters used in the models contributed significantly in estimating of MET. Results showed a confidence level of $\alpha=0.05$, indicate that marginal contribution of each variable is significant (table 4 ).

Results depicted in table 5, indicate that all performance criteria are improved; they show that the model will provide closer approximation of water needs at different development stages of wheat crop's lifecycle. Indeed, the Nash efficiency value is 0.92 . The mean squared error, root mean squared error and mean absolute relative error are respectively

\begin{tabular}{|l|r|l|c|r|r|l|}
\hline Parameters & T statistical & T critical & $\mathrm{R}^{2}$ & $\begin{array}{r}\text { AiF } \\
\text { observed }\end{array}$ & F Critical & Probability \\
\cline { 1 - 2 } Constant & $-6,61$ & 2.085 & $90 \%$ & 93,48 & 3.10 & $\mathrm{P}<0.001$ \\
\hline T & 7,04 & & & & & \\
\hline Kc & 8,08 & & & & & \\
\hline
\end{tabular}

Where $\mathrm{T}$ is the mean daily temperature $\left({ }^{\circ} \mathrm{C}\right)$ and $\mathrm{Kc}$ is the crop coefficient Table 4: Statistical results of the modelling 
Citation: Laaboudi A, Mouhouche B (2012) Water Requirement Modelling for Wheat under Arid Climatic Conditions. Hydrol Curr Res 3:130. doi:10.4172/2157-7587.1000130

Page 5 of 6

\begin{tabular}{|c|c|c|c|c|c|c|}
\hline Parameters & T statistical & T critical & $\mathrm{R}^{2}$ & F observed & F Critical & Probability \\
\hline Constant & $-5,27$ & \multirow[t]{4}{*}{2.085} & \multirow[t]{4}{*}{$92 \%$} & \multirow[t]{4}{*}{127,68} & \multirow[t]{4}{*}{3.10} & \multirow[t]{4}{*}{$P<0.001$} \\
\hline $\mathrm{T}$ & 2,47 & & & & & \\
\hline LAI & 5,56 & & & & & \\
\hline $\mathrm{Kc}$ & 5,50 & & & & & \\
\hline
\end{tabular}

Where $\mathrm{T}$ is the mean daily temperature $\left({ }^{\circ} \mathrm{C}\right), \mathrm{LAl}$ is the leaf area index and $\mathrm{Kc}$ is the crop coefficient

Table 5: Statistical results of the modelling

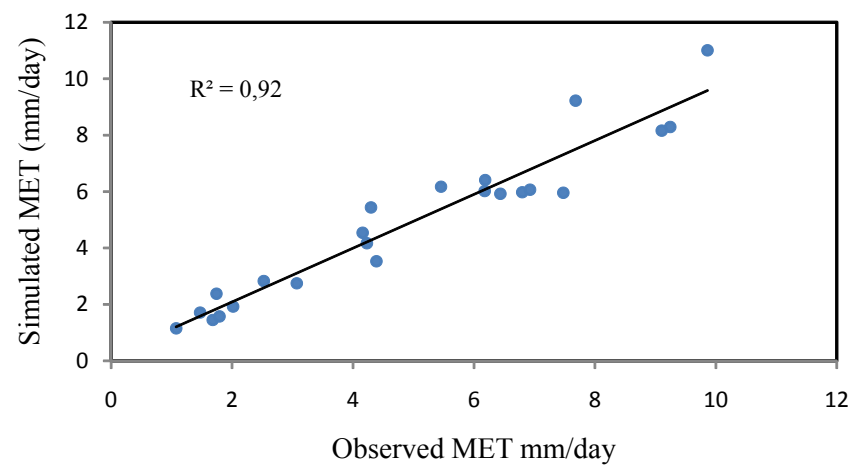

Figure 6: Correlation between Observed MET and simulated MET

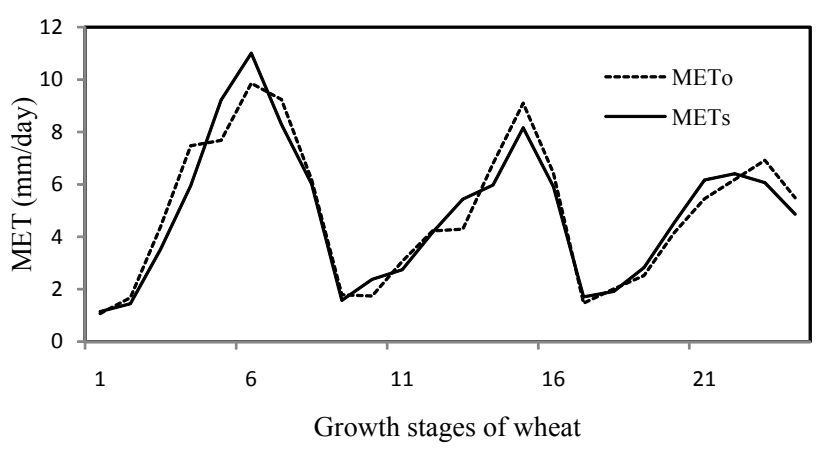

Figure 7: Graphical comarison between observed MET and simulated MET for différent growth stages of wheat

$0.56(\mathrm{~mm} / \text { day })^{2}, 0.75(\mathrm{~mm} /$ day $)$ and $12.76 \%$. This means the good relationship between observed MET and simulated MET (Figure 6).

The graphical comparison between the observed and simulated series of MET values reveals a high resemblance (Figure 7).

\section{Conclusion}

In Adrar conditions the most meteorological component which affects the water consumption for wheat is the temperature. That it is why; one can perform the effective temperature based model. Although MET depends on several factors, however, it was found that the average daily temperature is the most important. In the non linear relation, the leaf area index has also an impact on water consumption of wheat.

Therefore, the proposed model allows knowing on place, approximately at any time, the amount need of water for the wheat crop. The parameters used are easily available. For temperature, we can use the forecasts of weather services and for leaf area it is easily calculated by knowing the great width and length of blades.

This study will make it possible to determine when and where the wheat crop can be cultivated under rainfed conditions or irrigated conditions like in Adrar region of Algeria. It will play a key role for better management of water resources as well. This study will provide closer approximation of water needs at different development stages of wheat crop's life cycle. The models will be an effective tool for farmers and irrigators to practice a better management of water and contribute to save energy and water.

\section{References}

1. Zhao CY, Nan ZR, Cheng GD (2005) Methods for estimating irrigation needs of spring wheat in the middle Heihe basin, China. Agricultural Water Management 75: $54-70$

2. Chuanyan Z, Zhongren N, Guodong C (2005) Evaluating methods of estimation and modelling spatial distribution of evapotranspiration in the middle Heihe River Basin, China. Am J Environ Sci 1.

3. Clemmens AJ, Molden DJ (2007) Water uses and productivity of irrigation systems. Irrigation Science 25: 247-261.

4. Naeem M, Rai NA (2005) Determination of Water Requirements and Response of Wheat to Irrigation at Different Soil Moisture Depletion Levels. Int J Agric Biol 07: 812-815

5. Bharat RS (2006) Crop Water Requirements and Water Productivity Concepts and Practices. College of Agricultural Engineering, Punjab Agricultural University, Ludhiana.

6. Pereira LS, Oweis T, Zairi A (2002) Irrigation management under water scarcity. Agricultural water management 57: 175-206.

7. De Silva CS, Weatherhead EK, Knox JW, Rodriguez-Diaz JA (2007) Predicting the impacts of climate change--A case study of paddy irrigation water requirements in Sri Lanka. Agricultural water management 93: 19-29.

8. Doria R, Madramootoo CA, Mehdi BB (2006) Estimation of Future Crop Wate Requirements for 2020 and 2050, Using CROPWAT. EIC Climate Change Technology 1-6.

9. World Bank (2007) People's Democratic Republic of Algeria, Public expenditure review. Assuring high quality public investment. Document of the World Bank (in two volumes) volume I: Main report. Report no. 36270-dz, p213.

10. Chennafi H, Aidaoui A, Bouzerzour H, Saci A (2006) Yield response of Durum wheat (Triticum dirum Desf) Cultivar Waha to Deficit Irrigation under Semi Arid Growth Conditions . Asian J Plant Sci 5: 854-860.

11. Er-Raki S, Chehbouni A, Ezzahar J, Khabba S, Lakhal EK et al. (2011) Derived Crop coefficients for winter wheat using different reference evapotranspiration estimates methods. J Agr Sci Tech 13: 209-221.

12. Hajare HV, Raman NS, Jayant Dharkar ER (2008) New technique for evaluation of crop water requirement. WSEAS TRANSACTIONS on ENVIRONMENT and DEVELOPMENT 4: 436-446.

13. Chowdhary A, Shrivastava RK (2010) Reference Crop Evapotranspiration estimation using Artificial Neural Networks. International Journal of Engineering Science and Technology 2: 4205-4212.

14. Hunsaker DJ, Fitzgerald GJ, French AN, Clarke TR, Ottman MJ, et al. (2007) Wheat irrigation management using multispectral crop coefficients: II. Irrigation scheduling performance, grain yield. and water use efficiency. American Society of Agricultural and Biological Engineers 50: 2035-2050.

15. Shujiang K, William AP, Steven RE, Clay AR, Bobby AS (2009) Simulation of winter wheat evapotranspiration in Texas and Henan using three models of differing complexity. Agricultural Water Management 96: 167-178.

16. Reining E (2002) Leaf area index as non-destructive indicator of the development of cereals. Department of Land Use Systems and Landscape Ecology.

17. Allen RG, Pereira LS, Raes D, Smith M (1998) Crop EvapotranspirationGuidelines for computing crop water requirements. FAO Irrigation and Drainage Paper 56. Food and Agriculture Organization 1-15.

18. Krause P, Boyle DP, Base F (2005) Comparison of different efficiency criteria for hydrological model assessment. Advances in Geosciences 5: 89-97.

19. Rifkin PA, Holden S, Evans PE, Wright A (2001) Growth attributes for higher wheat yields in the high rainfall zone of south-western Victoria. Australian society of agronomy. 
Citation: Laaboudi A, Mouhouche B (2012) Water Requirement Modelling for Wheat under Arid Climatic Conditions. Hydrol Curr Res 3:130. doi:10.4172/2157-7587.1000130

20. Amjad H, Shazia N, Tahira I, Hina S, Ahsanul H (2008) Effects of $\mathrm{NaCl}$ salinity on seedling growth, senescence. catalase and protease activities in two wheat genotypes differing in salt tolerance. Pak J Bot 40: 1043-1051.

21. Bavec M, Vuković K, Grobelnik S, Rozman Č, Bavec F (2007) Leaf area index in winter wheat: response on seed rate and nitrogen application by different varieties. Journal Central European Agriculture 8: 337-342.

22. Charles AS, Paul B (2009) Determination of Evapotranspiration (ET) for Desert Durum Wheat using Weighing Lysimeters in the Lower Colorado River Region.
23. Bing L, Wenzhi Z, Xuexiang C, Shoubo L, Zhihui Z, et al. (2010) Water requirements and stability of oasis ecosystem in arid region, China. Environmental Earth Sciences 59: 1235-1244.

24. Tyagi NK, Sharma DK, Luthra SK (2000) Evapotranspiration and crop coefficients of wheat and sorghum. Journal of Irrigation and Drainage Engineering 126: 215-223.

25. Zhang Y, Yu Q, Liu C, Jiang J, Zhang X (2004) Estimation of winter wheat evapotranspiration under water stress with two semiempirical approaches. Agron J 96: 159-168. 